\title{
COUPLED ELECTROMAGNETIC-THERMAL SIMULATION OF A POWER TRANSFORMER BY 3D FEM
}

\author{
Henrique de Oliveira Henriques ${ }^{a}$, Carlos Eduardo Vizeu ${ }^{b}$, \\ Paulo César de Souza ${ }^{c}$, Maurício Caldora Costa ${ }^{d}$, \\ Guilherme Gonçalves Sotelo ${ }^{a}$, Jonaylton Moura de Sousa ${ }^{a}$, \\ Marcio Zamboti Fortes ${ }^{a, *}$, Vitor Hugo Ferreira ${ }^{a}$ \\ ${ }^{a}$ Fluminense Federal University, Engineering School, Electrical Engineering Department, 24210-240 Niteroi, RJ, \\ Brazil \\ ${ }^{b}$ Aires Consulting, Engineering Department, 20000-000 Rio de Janeiro, RJ, Brazil \\ ${ }^{c}$ Light Serviços de Eletricidade S. A., High Voltage Maintenance and Operation Department, 27175-000 Pirai, \\ RJ, Brazil \\ ${ }^{d}$ Electromagnetics Tecnologia, Engineering Department, 09750-730 São Bernardo do Campo, SP, Brazil \\ * corresponding author: mzamboti@id.uff.br
}

\begin{abstract}
Power transformers are the most common equipment in an electric power system, which has been manufactured in the last decade. However, overheating can damage them, considerably reducing their operation lives, which may cause economic losses to the power utilities. The motivation of this paper is to investigate the time and power overload limits that a power transformer can be subjected to and how it will impact its temperature. Investments in the grid can be delayed if a transformer can support some overload during some momentary load demand increase. In this context, this paper presents a study of a 30/40 MVA power transformer by 3D finite element method (FEM) for coupled thermal-electromagnetic simulations to investigate its thermal behaviour when it is submitted to its nominal load at a steady-state operation and a variable load during a period of one day. The simulations were performed with the commercial software packages Flux 3D and AcuSolve, for electromagnetic and thermal modelling, respectively. The modelled equipment was based on a power transformer installed in the Light Serviços de Eletricidade S.A, the utility that supplies electrical energy to the city of Rio de Janeiro, in Brazil. Since the literature doesn't present many works simulating coupled thermal-electromagnetic power transformers in 3D-FEM, this paper has the goal to bring new contributions to this field. Three study cases were modelled, and some simplifications in transformer's geometry were made in some of them to reduce the computation time usually required for such a simulation. The obtained results are presented and compared with the measured values for the temperature in the hot spot of the transformer and in the top of the oil, to investigate the impact of these simplifications in the calculated results.
\end{abstract}

Keywords: Power transformer, thermal simulation, finite element method, hot spot, CFD.

\section{INTRODUCTION}

Power transformers are the costliest equipment in the process of expanding system substations [1]. The distribution companies allocate millions of dollars in their expansion plan for the acquisition of new equipment, which, due to its high cost, should be used to its maximal potential in its capacity to transport energy and, at the same time, have ensured its integrity throughout the expected period of time for its service life [2, 3]. The integrity warranty is directly related to the temperature limits that the power transformer insulations may be subjected to during normal and emergency operation conditions [4].

The literature presents some papers dedicated to simulating a power transformer using a finite element method (FEM) considering the model-based in the thermal properties [5-10] and electromagnetic phenomena [11 15]. Some other papers also inves- tigate coupled thermal electromagnetic modeling of the equipment [16, 17]; however, the literature is still limited. In this context, the contribution of this work is to present a tridimensional numerical modeling to simulate one power transformer by coupling the electromagnetic and thermal behaviour, covering a gap in this field. The 3D model can be used by electrical energy distribution companies to predict the hot spot temperature in typical daily cycles of operation and regions with a high concentration of load. The model was implemented in the commercial software AcuSolve [18] that uses the 3D FEM and Computational Fluid Dynamics (CFD) [19 formulation to simulate the oil movement and the heat flow inside the transformer.

In a previous work [20, a model, where the heat exchange between the main parts of the transformer (core, windings, and tank) and the insulating oil was 
considered through the phenomenon of thermal convection, was developed. In that case, the convective coefficients were analytically calculated for the surfaces of these parts in contact with the oil, representing a complex task susceptible to the inaccuracy of the results. Moreover, in that previous work, the oil circulation inside the transformer was not considered, since the computational tool used in the simulation didn't have the necessary resources to simulate the fluid dynamics.

In this new study, we decided to use a tool dedicated to thermal simulation in fluids, in order to consider the oil movement inside the transformer and also allowing the automatic calculation of the convective coefficients for the heat flux exchange between the windings and core walls, and the insulating oil, warranting a better accuracy of the results.

However, due to the main disadvantage of the CFD tools, which is the need for very high computation time, mainly due to a large number of mesh elements normally required by this kind of simulation. a simplified model of the transformer was developed, as will be detailed in the next sections.

The validation of the developed model was made through the temperature determination in the hot spot for the condition of the transformer operating at its nominal load of 30/40 MVA, natural and forced ventilation respectively. The hot spot and top oil temperatures were monitored when the transformer was submitted to a variable load curve for 5 hours and 30 minutes. The power demanded by the load changed from 27.8 MVA to 30 MVA during the tests. The FEM coupled simulations were performed to reproduce these operational conditions comparing three different ways of modelling the windings and the radiator, in which some simplifications were applied. The proposed simplifications to the coil and the radiator had an impact on the accuracy of the results, as will be shown in the following sections.

\section{Methodology}

The 3D computational model of a power transformer was developed using Flux3D, a finite element package for electromagnetic simulations, and the AcuSolve software, a CFD tool dedicated to thermal simulations. The model was developed considering the main geometric and physical characteristics of the transformer, including its core, the high and low voltage windings, and the transformer tank.

Two main heat sources were considered in the model: the core losses and the windings losses. The core losses represent the no-load losses, they were calculated through an electromagnetic simulation, and they can be considered constant even for a variable load. The windings losses represent the losses due to the Joule effect in the coils, and they are proportional to the winding electric resistance and the current flowing through the windings, meaning it is dependant on the load curve.
The induced currents in the transformer tank and the effects of solar radiation were not included in this simulation model, although they represent heat sources existing in real conditions.

Concerning the heat dissipation from the transformer to the environment in the model, it was considered through a convective heat flux coefficient defined for the tank walls and another one for the radiator walls, where the most significant parcel of heat dissipation is.

All convective heat flux coefficients that modell the thermal exchange between the insulating oil and the surface of the transformer components (core, windings, and tank) were automatically calculated by the simulation software.

The insulating oil circulation inside the transformer was modelled through a natural convection phenomenon using the Boussinesq model [10 with laminar flow, once the transformer was considered operating with the type of the refrigeration ONAN (Oil Natural, Air Natural) [19, 21.

The transformer was simulated operating with a variable load close to its nominal load of $30 \mathrm{MVA}$. For this simulation, we used the Transient Analysis with a time step of 60 seconds. It must be noted that a preliminary study was made to determine the value of the time step that ensures a reduction in the computation time without compromising the quality of the results.

\section{MODEL DESCRIPTION}

The transformer used for the development of the $3 \mathrm{D}$ finite element model is a $30 / 40 \mathrm{MVA}, 138 / 13.8 \mathrm{kV}$, $\Delta / \mathrm{Y}$, three-phase transformer. Figure 1 presents a photo of the transformer that was simulated and measured in this work. Details of the equipment used for the model validation are presented in Table 1 with some data given by the utility and the manufacturer. This transformer is installed in one of the distribution substations of LIGHT S.A. - the main electric energy distribution company of Rio de Janeiro - Brazil. As described before, the model was developed in both Flux3D and AcuSolve software, commercial tools dedicated to electromagnetic and thermal simulations using the CFD, and it was carried out in different steps, including the geometry description, the finite element mesh generation, and the physical properties definition, as described in the following sections.

\subsection{Geometry}

Figure 2 shows the geometries used in the model to simulate the transformer, where one can identify the core (blue) and the coils of high (red) and low voltage (yellow) windings. One can see that the windings were modelled in two different ways: as continuous cylindrical structures - as shown in Figure 2a that is without the spacing between turns, existing in practice, and as segmented coils - as presented in Figure 2b. which is a more realistic approach. In both cases, 


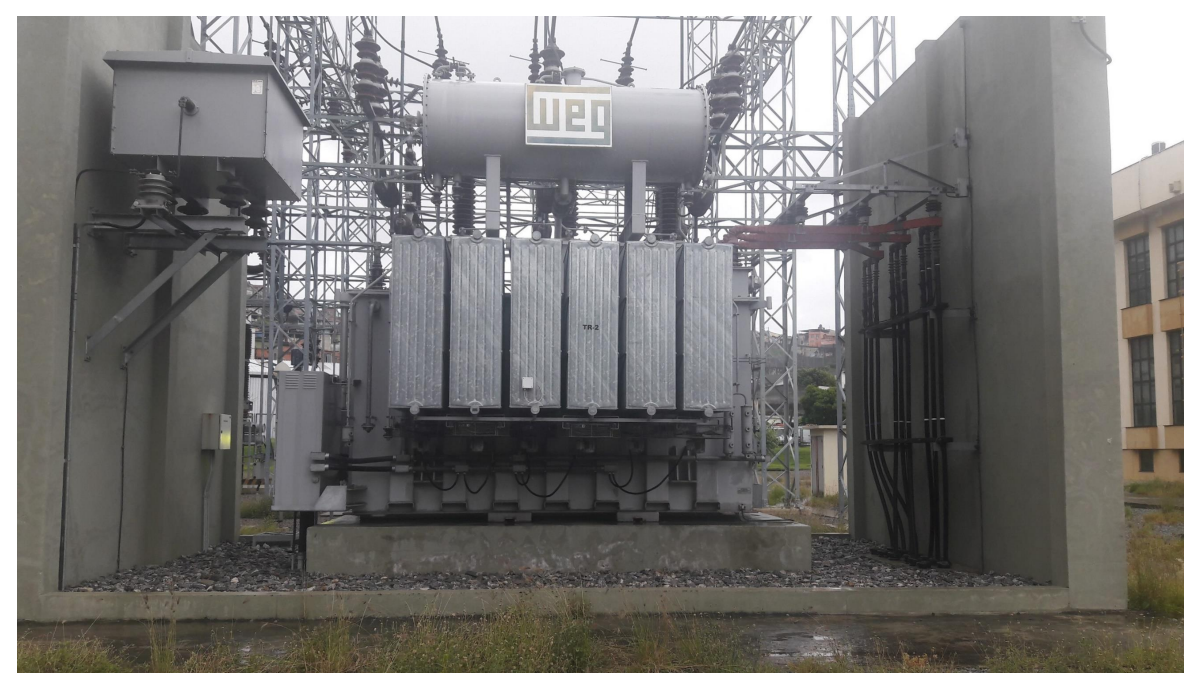

Figure 1. Picture of the 30/40 MVA, 138/13.8kV Power Transformer studied in this work.

\begin{tabular}{lc}
\hline Description & Value \\
\hline Voltage & $138 / 13.8 \mathrm{kV}$ \\
Power (greater power in forced ventilation) & $30 / 40 \mathrm{MVA}$ \\
Manufacturer & WEG \\
Class & $55{ }^{\circ} \mathrm{C}$ \\
Type of oil & Naphthenic \\
\hline Total mass & $63,600 \mathrm{~kg}$ \\
Active part mass & $25,500 \mathrm{~kg}$ \\
Core mass & $15,400 \mathrm{~kg}$ \\
Total oil mass & $17,000 \mathrm{~kg}$ \\
\hline Oil tank volume & $16.26 \mathrm{~m}^{3}$ \\
Oil volume into the radiator & $1.94 \mathrm{~m}^{3}$ \\
Total oil volume & $19.0 \mathrm{~m}^{3}$ \\
Copper losses & $200 \mathrm{~kW}$ \\
Core losses & $20 \mathrm{~kW}$ \\
Total losses & $220 \mathrm{~kW}$ \\
Equivalent resistance & $2.38 \Omega$ \\
\hline Radiator placing & Front $/ \mathrm{rear}$ \\
Number of heatsink units & $6+6$ \\
Tank area & $54.11 \mathrm{~m}{ }^{2}$ \\
Heatsinking unit area & $55.17 \mathrm{~m}^{2}$ \\
\hline
\end{tabular}

TABLE 1. Technical data of the power transformer measured in the field and used for the model validation.

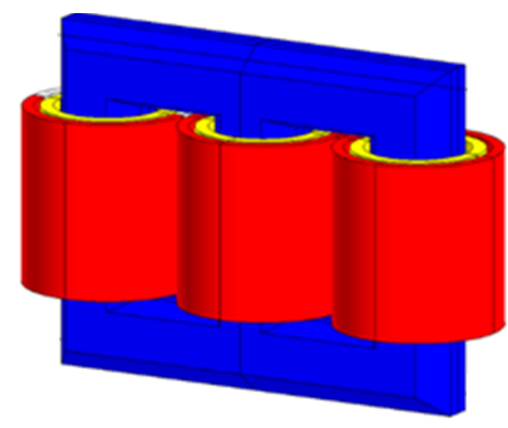

(A).

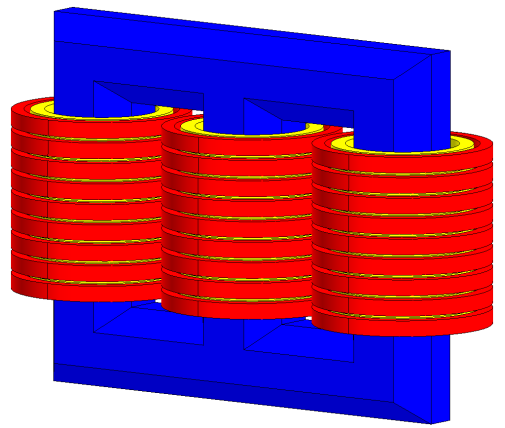

(B).

Figure 2. (A) The geometry of the full core and simplified windings representation. (B) More realistic windings represented in segmented coils turns. 
the windings were modelled with an additional shell region with 4 layers of $0.3 \mathrm{~mm}$, representing their cover of paper insulation with a thermal conductivity of $0.19 \mathrm{~W} / \mathrm{m} \cdot \mathrm{K}$. The goal of modelling the coils by these two different ways is to compare the importance of the coil details' influence on the simulated results.

The power transformer was modelled considering its full geometry for the electromagnetic FEM simulations to calculate the core losses. However, due to the existing symmetry in the transformer, the geometry adopted in the thermal simulations was only $1 / 4$ of the real one, as presented in Figure 3 The reason behind this decision is to reduce the degrees of freedom of this problem and, consequently, the computational effort. This simplification made it possible to reduce the simulation time without compromising the quality of the results, since the observed physical phenomenon allows such a consideration. Another component added to the simulation model is the radiator that makes the main heat exchange between the hot oil on the top of the transformer and the external environment. The radiator has a complex geometry formed by several thin cooling fins, which are very small when compared to the other parts of the transformer. This results in a high number of mesh elements that consequently increase the simulation time. In order to investigate how important is the radiator shape, three different approaches were proposed. In the first attempt, named as case $\mathrm{A}$, the radiator was modelled using cylindrical tanks where the heat exchange with the external air is made through their walls, where a high convective heat flux coefficient of $h_{c}=450 \mathrm{~W} / \mathrm{m}^{2} \mathrm{~K}$ was defined. In case $\mathrm{A}$, besides the radiator, the windings were simplified. The second approach proposed is presented in Figure 3b named as case B. Here, the radiator has the same volume of the real device, but a rectangular shape and an intermediate convective heat flux coefficient of $h_{c}=170 \mathrm{~W} / \mathrm{m}^{2} \mathrm{~K}$ was assumed. Finally, case $\mathrm{C}$ presents a form similar to the real transformer, as shown in Figure 3c The radiator was modelled by 12 rectangular plates and with convective heat flux coefficient of $h_{c}=27.2 \mathrm{~W} / \mathrm{m}^{2} \mathrm{~K}$. Cases B and $\mathrm{C}$ consider the windings represented in segmented coils turns. For all simulated cases, the radiator was modelled with six tanks on each side of the transformer (three tanks in 1/4 of geometry), representing the number of oil outputs existing in the real transformer. The goal of this comparison is to investigate how these windings and radiator simplifications are relevant to the accuracy of the results.

\subsection{Finite Element MESH}

The finite element mesh generation is one of the most critical steps in the development of the model, the quality of the results is directly related to the quality of the mesh. As discussed earlier, some simplifications were incorporated into the geometry (mainly that of the core and windings) aiming to obtain a quality mesh without increasing the number of elements and, consequently, the computation time. The radiator was also considered with a simplified geometry composed by cylinders, since the detailing of all cooling fins would result in an extremely high number of elements.

The tridimensional mesh used in the model is composed of tetrahedral elements, resulting in the following number of nodes in $1 / 4$ of the transformer geometry for each case: $A=155370, B=341221$, $C=347567$. Even with the geometry simplifications considered in the model, the thermal simulation involving computational fluid dynamics (CFD) requires a greater refinement of the mesh, especially in the regions near the walls of the tank, coils, and core, where the heat exchange between those parts and the insulating oil through the thermal convection phenomenon takes place. Those regions require the use of a mesh formed by elements layers to correctly modell the fluid flow, as shown in Figure 4.

\subsection{PhysicAl PROPERTIES}

Physical properties were defined to describe the thermal behaviour of six main regions: core, high voltage winding, low voltage winding, oil, tank, and radiator.

The core was defined as a region with thermal conductivity of steel $(150 \mathrm{~W} / \mathrm{m} \cdot \mathrm{K})$, and with a heat source equivalent to the no-load losses calculated through the electromagnetic simulation, estimated as $20 \mathrm{~kW}$. This represents about $15 \%$ of the total losses when the transformer is under its nominal load (30 MVA).

The high and low voltage windings are regions with the same thermal properties as copper, i.e., thermal conductivity $k=394 \mathrm{~W} / \mathrm{m} \cdot \mathrm{K}$ and volumetric thermal capacity $c_{p}=3.52 \mathrm{E} 6 \mathrm{~J} / \mathrm{m}^{3} \cdot \mathrm{K}$. The heat source in the windings was calculated from their Joule losses, and it depends on the electrical resistance and the current flowing in the winding (obtained from the transformer's load curve). Under the nominal load, the windings losses are $112.5 \mathrm{~kW}$. Figure 5 shows the power transformer load curve for a period of almost 30 hours. The temperature measurements were done in this interval between 10:05 $\mathrm{h}$ and 15:30 $\mathrm{h}$.

The oil region has the same thermal conductivity of the mineral oil used in transformers, i.e., $0.1262 \mathrm{~W} / \mathrm{m} \cdot \mathrm{K}$. It has a specific heat capacity of $2100 \mathrm{~J} / \mathrm{kg} \cdot \mathrm{K}$, a viscosity of $0.00738 \mathrm{~kg} / \mathrm{m} \cdot \mathrm{s}$ and a volumetric density of $848 \mathrm{~kg} / \mathrm{m}^{3}$. The thermal properties of the oil were considered constant, while the variation of its density was modelled through the Boussinesq model [10]. Its expansivity was considered with a value of $0.00064{ }^{\circ} \mathrm{C}^{-1}$, aiming to represent the natural convection phenomenon.

The tank represents the region of the transformer in contact with the air, where the part of the heat dissipation by convection and radiation takes place. The heat flux density dissipated from the tank by natural convection depends on the air temperature immediately in contact with the tank walls and the convective heat flux coefficient $h\left[\mathrm{~W} / \mathrm{m}^{2} \cdot \mathrm{K}\right]$, as indicated in the equation below. As described before, the 


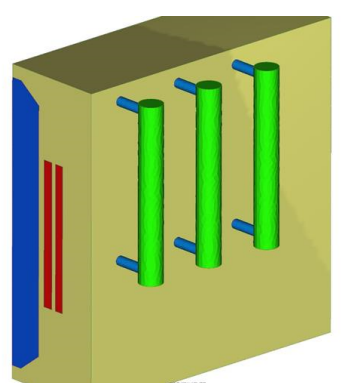

(A).

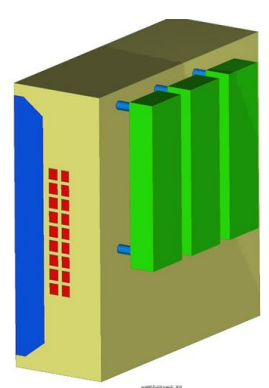

(B).

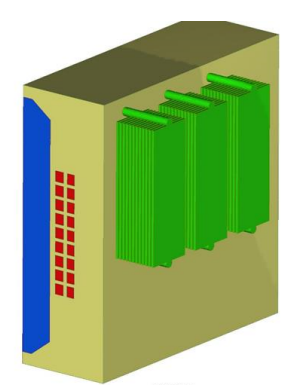

(C).

Figure 3. Geometry used to modell the radiator. (A) Case A - cylindrical simplified radiator with $h_{c}=450 \mathrm{~W} / \mathrm{m}^{2} \mathrm{~K}$ and simplified winding; (B) Case B - rectangular simplified radiator with $h_{c}=170 \mathrm{~W} / \mathrm{m}^{2} \mathrm{~K}$; (C) Case C -radiator with 12 plates and $h_{c}=27.2 \mathrm{~W} / \mathrm{m}^{2} \mathrm{~K}$, similar to the real device.

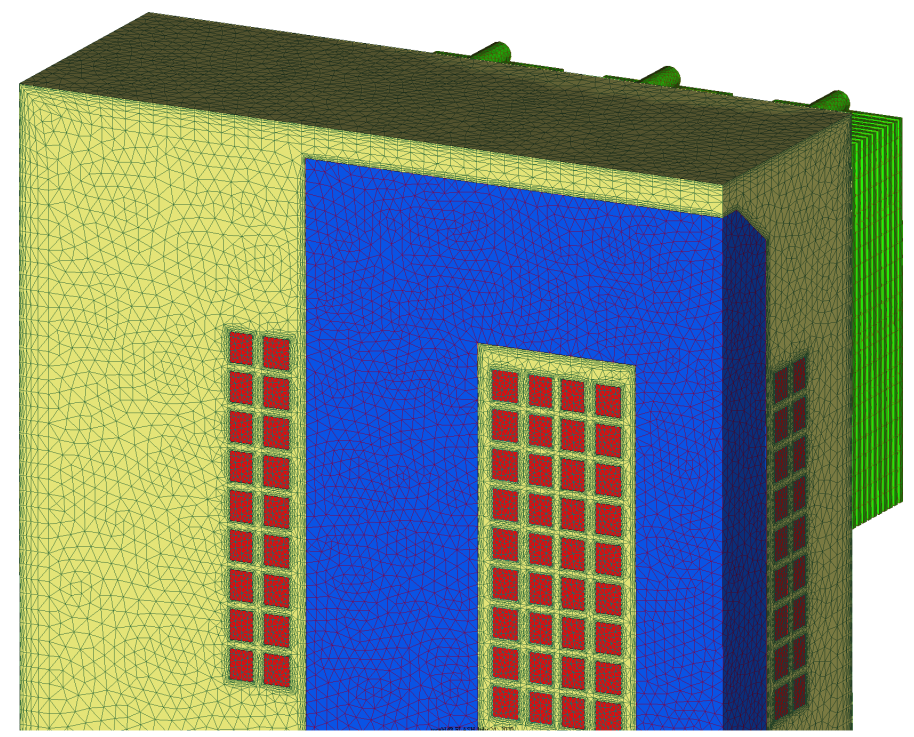

FIGURE 4. Detail of the finite element mesh used to the thermal simulations of case C.

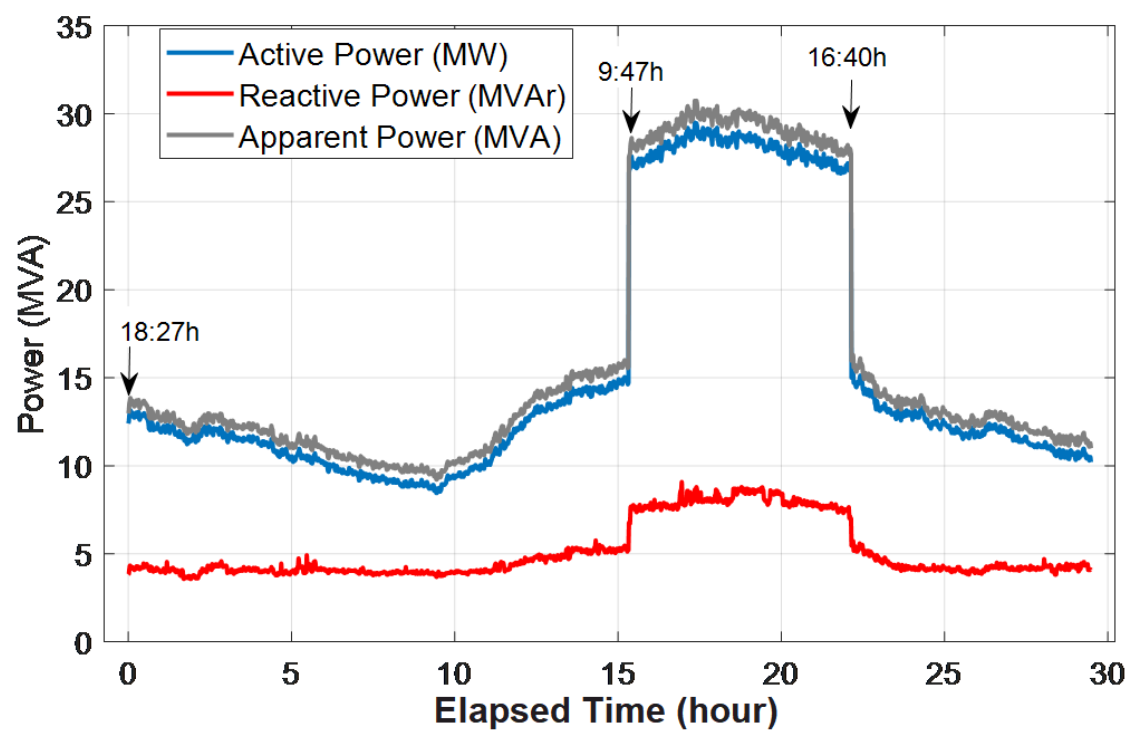

Figure 5. Measured load curve used to validate the FEM simulations. 
induced currents in the tank walls and the solar radiation during the daytime period weren't considered as heat sources in this simulation model.

$$
\varphi=-h \cdot\left(T_{w}-T_{a}\right)
$$

where:

$$
\begin{aligned}
& \varphi \text { - heat flux density (normal to the surface) }\left[\mathrm{W} / \mathrm{m}^{2}\right] \\
& h \text { - convective heat flux coefficient }\left[\mathrm{W} / \mathrm{m}^{2} \cdot \mathrm{K}\right] \\
& T_{w} \text { - the temperature of the tank wall }[\mathrm{K}] \\
& T_{a} \text { - the temperature of ambient air }[\mathrm{K}]
\end{aligned}
$$

Besides the heat exchange between the tank walls and the external air, the developed model considers the heat dissipation from the windings to the insulating oil through a natural convection. To this end, the AcuSolve software automatically computes the convective coefficients for these faces, so it isn't necessary to calculate them analytically. This automatic calculation represents a significant improvement when compared to the previous work [20, where it was necessary to calculate the value of the convective heat flux coefficients analytically for each face of the geometry in contact with the oil.

Finally, the radiators were described in the simulation model as a region where the surfaces in contact with the ambient air have a high convective coefficient dependent on the modelled case, as described in the legend of Figure 3

\section{Results}

\subsection{Electromagnetic FEM results}

As mentioned above, the electromagnetic simulations were calculated using the Flux3D software. For these simulations, the authors didn't apply any symmetry to reduce the degrees of freedom of the problem. From the electromagnetic point of view, the Cases A, B, and $\mathrm{C}$, will yield the same results because the same Magnetomotive force is applied to the core in all cases. Figure 6 presents the magnetic flux density in the core of the transformer. This result was calculated considering that the transformer is feeding a load of 30 MVA. It can be observed that the transformer is operating at a point immediately after its saturation, at the maximum magnitude around $2.1 \mathrm{~T}$.

The losses with the nominal load are presented in Figure 7 These values give the iron losses contributions to the heating of the oil. The total iron loss calculated without load is $20.2 \mathrm{~kW}$. The expected loss, given by the manufacturer's specifications, for the transformer operating with no load is $20 \mathrm{~kW}$, so a difference of only $1 \%$ was verified in this case.

\subsection{Thermal FEM REsults}

In this section, we present the results obtained from the thermal simulation. Figure 8 shows the temperature colour map on the surface of the windings and the transformer core for the case where it is operating with the load curve shown in Figure 5 , for the same amount of time (about 20 hours). It is possible to see that the warmer region is in the internal coils of the windings, where the temperature is close to $77.5^{\circ} \mathrm{C}$ for the case A, $74.2{ }^{\circ} \mathrm{C}$ for the case $\mathrm{B}$ and $68.5^{\circ} \mathrm{C}$ for the case C. Figure 9 shows the obtained temperature only on the surface of the core (maximum value $=$ $\left.68.8^{\circ} \mathrm{C}\right)$.

Figure 10 shows the temperature colour map along a vertical plane inside the transformer tank, where it is possible to see the oil temperature variation from the bottom to the top of the transformer. In this figure, it can be observed that the temperature at the top of the oil is about $63.8^{\circ} \mathrm{C}$ (case A), $62.4^{\circ} \mathrm{C}$ (case B) and $54.0^{\circ} \mathrm{C}$ (case C), i.e., approximately $12^{\circ} \mathrm{C}$ $15^{\circ} \mathrm{C}$ below the temperature of the hot spot for each case.

Figure 11 shows the oil flow vectors in the inlet and outlet ducts of the radiator cylinders. The legend of this figure represents the temperature value of these vectors, and it is possible to verify a temperature variation of approximately $11^{\circ} \mathrm{C}$ between the oil temperature at the inlet of the radiator and the average oil temperature at its outlet in the three simulated cases.

Figure 12 shows the comparison between the measured temperatures at the top of the oil and the simulated results for the Cases A, B, and C. It can be seen that cases $\mathrm{A}$ and $\mathrm{B}$ could not represent the experimental data very well. On the contrary, Case C could obtain a result much closer to the actual measurements, in which the highest error was $12.4 \%$. This figure also presents the measured room temperature in the substation and the apparent power demanded by the load supplied by this transformer. The forced ventilation was turned on automatically at 12:15 h, turned off manually 13:36 h, and turned on (again manually) at 14:41. The external temperature and the forced ventilation effects were taken into account in the model.

The hot spot temperatures were also measured and simulated, as can be seen in Figure 13 Again, the case $\mathrm{C}$ was the only one that could show a satisfactory temperature result, with a maximum error of $8.5 \%$. These results were obtained using the transient analysis, as described in section 3 , and one can see that the hot spot has a similar temperature variation as the load.

\section{Conclusions}

A three-dimensional finite element model was developed in order to simulate the thermal behaviour of a three-phase 30/40 MVA power transformer subjected to a steady-state operation, supplying a variable load around the rated power. Some simplifications in geometry were made to reduce the number of elements in the mesh and the computation time. The simplifications did reduce the computation demands, but 

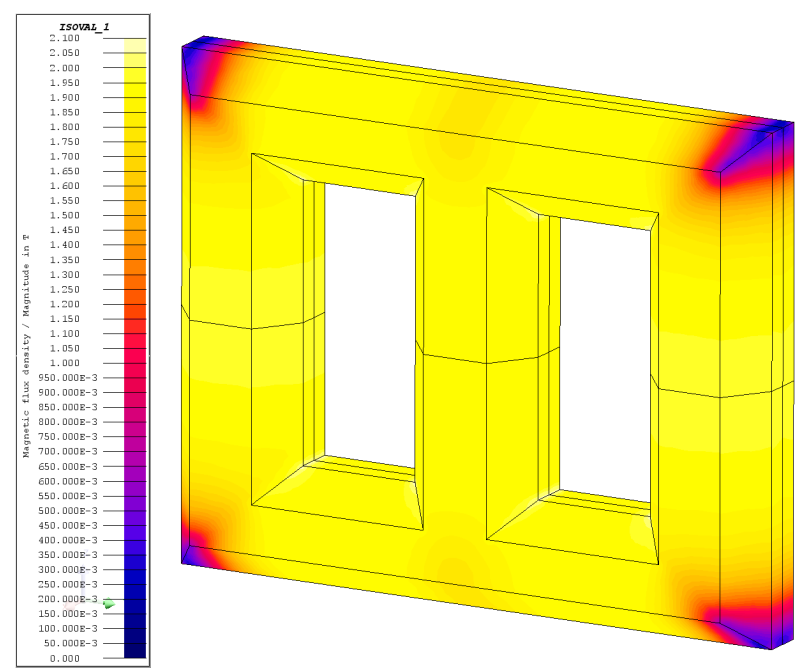

(A).
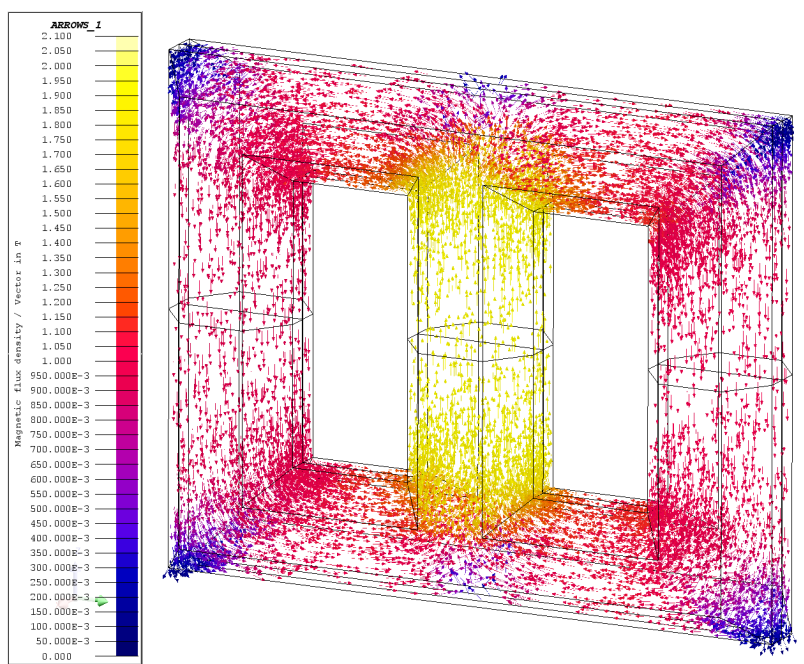

(в).

Figure 6. Magnetic flux density in the core region: (A) Modulus of B; (B) Vector representation.

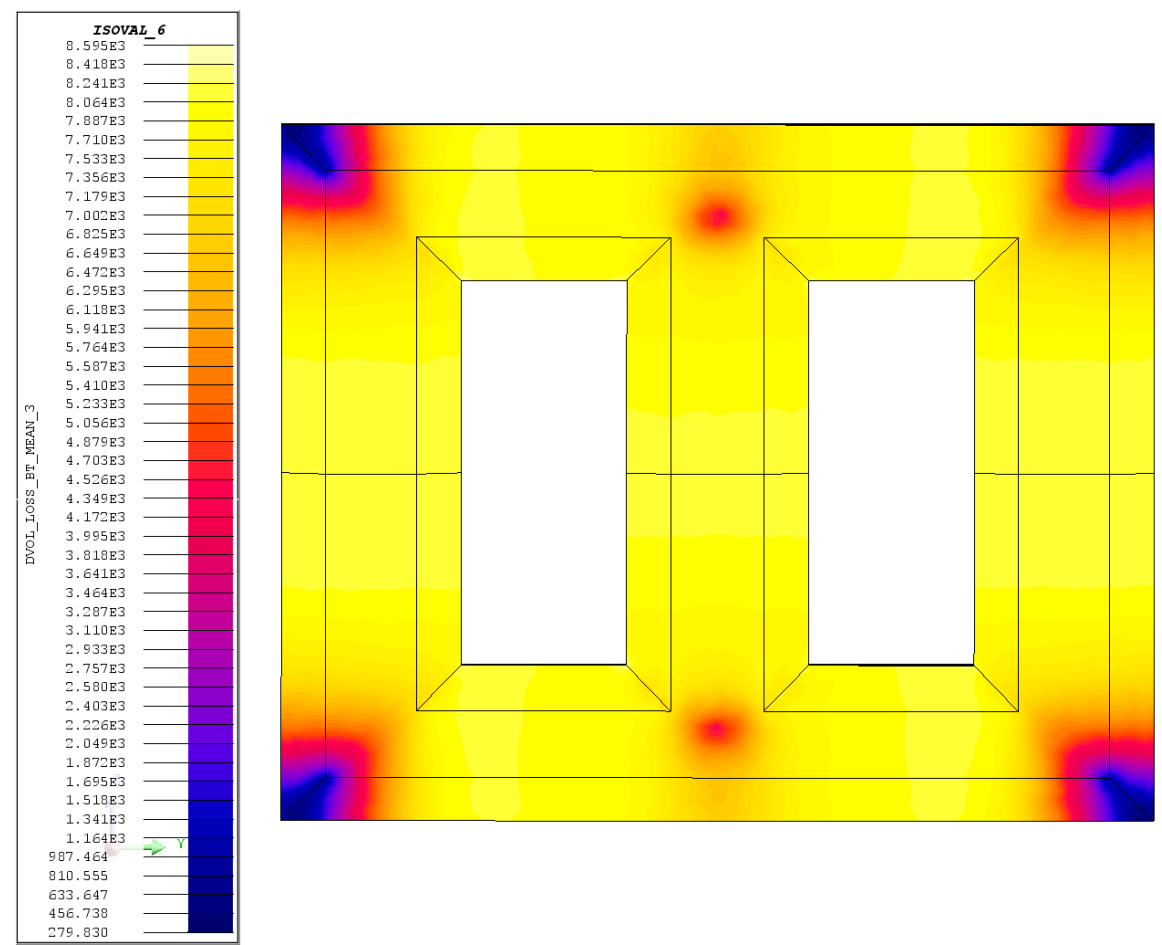

FiguRE 7. Total iron power losses with nominal load. 


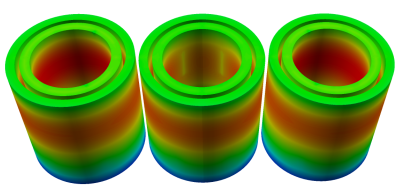

(a)

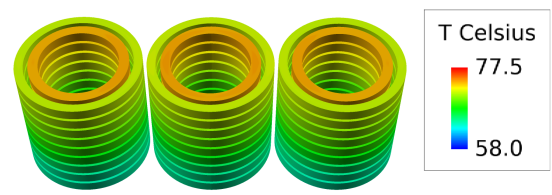

(b)

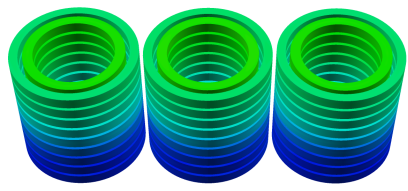

(c)

Figure 8. Temperature colour map on windings and core (nominal load) (a) Case A; (b) Case B; (c) Case C.
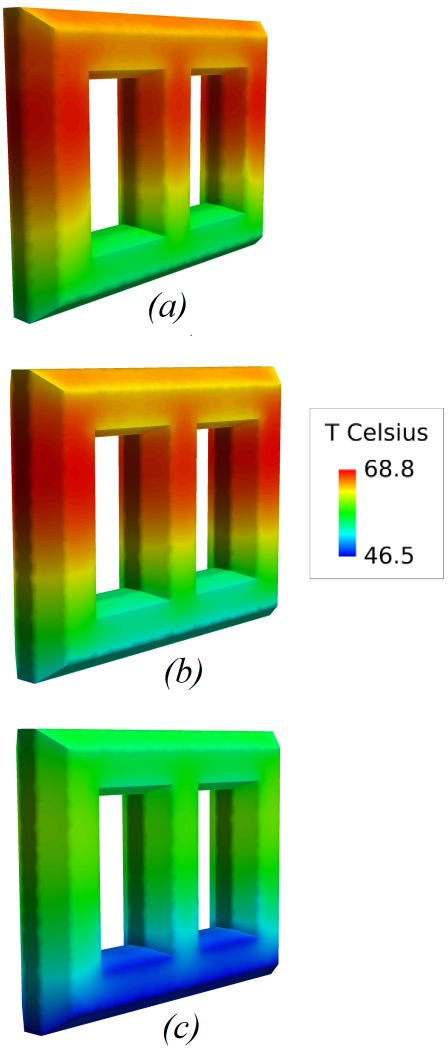

Figure 9. Temperature colour map on the core (nominal load) (a) Case A; (b) Case B; (c) Case C.

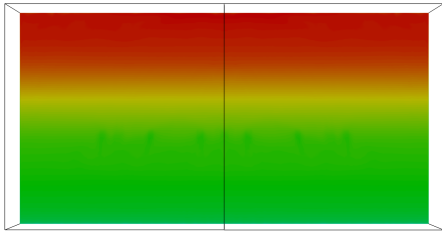

(a)

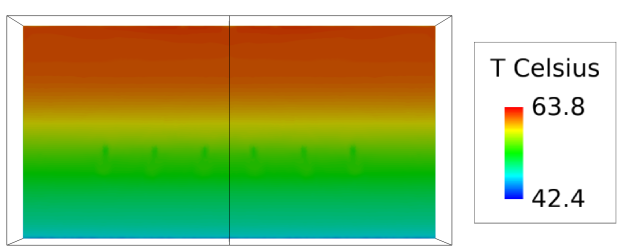

(b)

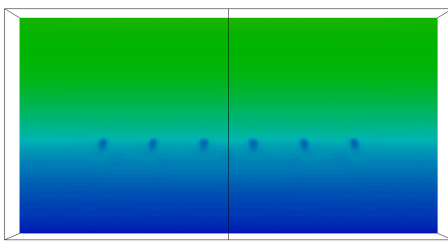

(c)

Figure 10. Colour map of the oil temperature from the bottom to the top (nominal load) (a) Case A; (b) Case B; (c) Case C.
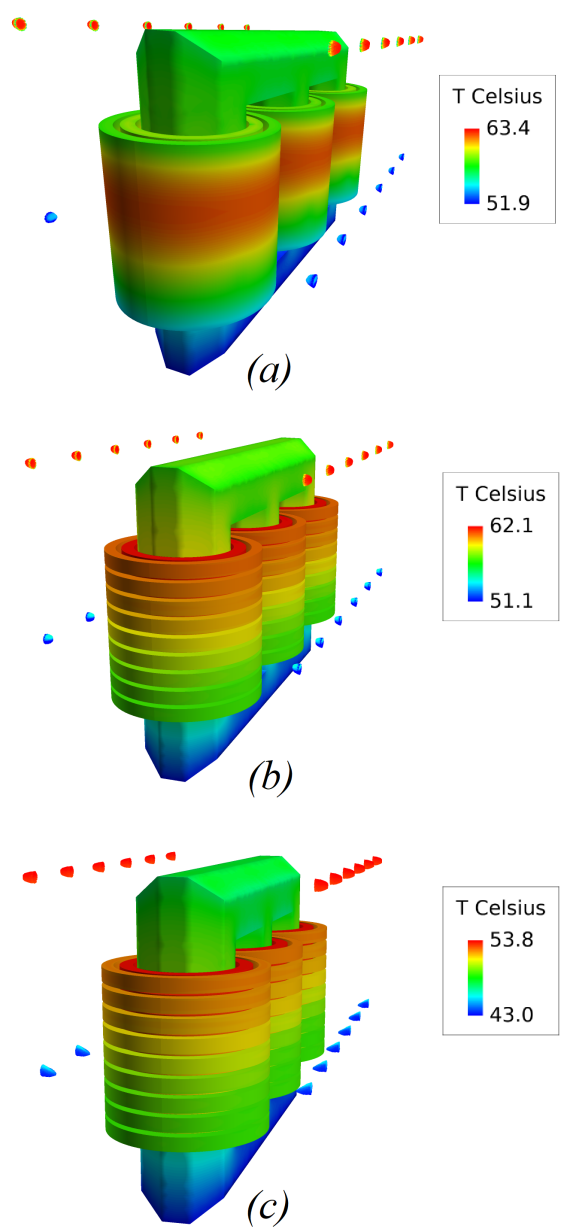

FIgURE 11. Inlet and outlet oil temperature (nominal load): (a) Case A; (b) Case B; (c) Case C. 


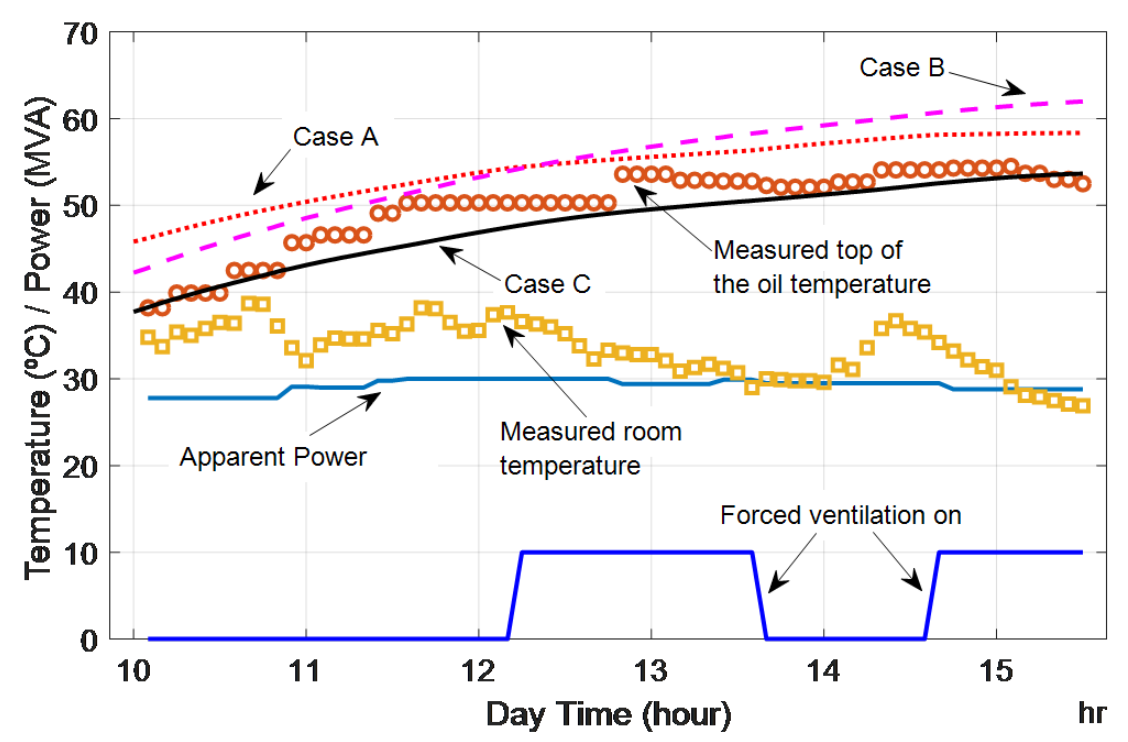

Figure 12. Top of the oil temperature for a variable load.

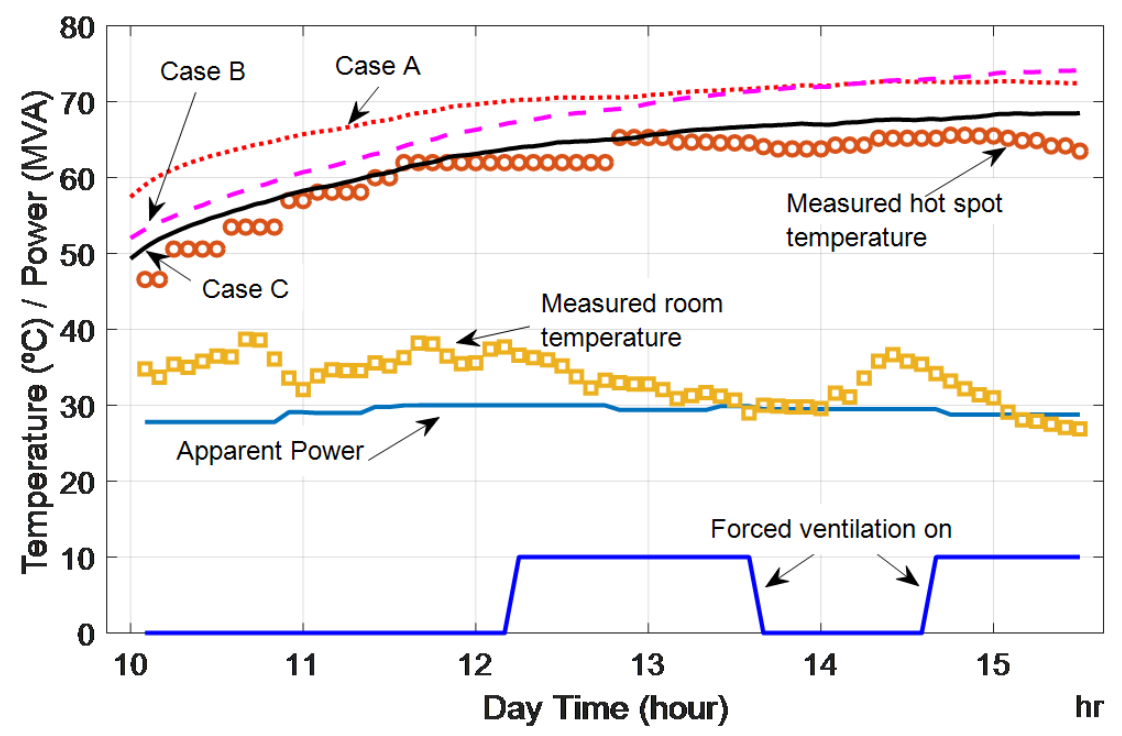

Figure 13. Hot spot temperature for a variable load.

they had a severe impact on the accuracy of the simulations. The obtained results indicate that a precise representation of the winding is relevant to obtain a maximum acceptable error (around 10\%) between the measurements and the simulations.

The temperature curve obtained in the simulations exhibited a very similar behaviour to the experimental curves, including the obtained temperature of the windings. However, only the case, in which the windings and the radiators were represented with the same level of details of a real transformer, could be validated. For this case, the maximum temperature discrepancy between the measurements and the simulations was around $8.5 \%$ for the hot spot point in the coil and $12.4 \%$ for the top of the oil. The discrepancies could be even reduced by a more detailed representation of the windings, core, and radiator. The following items can be improved: representing core laminations, modelling all the coil turns and the space between them, and considering the roughness of the surface in the radiator. However, the average time to carry out these $3 \mathrm{D}$ simulations is around 1 or 2 days on a personal computer with i7 $(2.9 \mathrm{GHz})$ processor, $16 \mathrm{~Gb}$ of RAM, and $4 \mathrm{~GB}$ of VRAM. The representation of those details could reduce the error, but the simulation time would increase considerably.

\section{ACKNOWLEDGEMENTS}

The authors would like to thank ANEEL/Light Serviços de Eletricidade S.A. (R\&D Project $n^{\circ} 106 / 2018$ ) for the financial and technical support in the development of this paper. 


\section{REFERENCES}

[1] S. K. Khator, L. C. Leung. Power distribution planning: a review of models and issues. IEEE Transactions on Power Systems 12(3):1151 - 1159, 1997. DOI:10.1109/59.630455

[2] G. W. Swift, E. S. Zocholl, M. Bajpai, et al. Adaptive transformer thermal overload protection. IEEE Transactions on Power Delivery 16(4):516 - 521, 2001. DOI:10.1109/61.956730

[3] J. A. Jardini, J. L. P. Brittes, L. C. Magrini, et al. Power transformer temperature evaluation for overloading conditions. IEEE Transactions on Power Delivery 20(1):179 - 184, 2005. DOI:10.1109/TPWRD.2004.835433

[4] A. J. Christina, M. A. Salam, Q. M. Rahman, et al. Causes of transformer failures and diagnostic methods a review. Renewable and Sustainable Energy Reviews 82:1442 - 1456, 2018. DOI:10.1016/j.rser.2017.05.165

[5] R. Sitar, I. Šulc, Žarko Janić. Prediction of local temperature rise in power transformer tank by fem. Procedia Engineering 202:231 - 239, 2017. DOI:10.1016/j.proeng.2017.09.710

[6] N.-C. Chereches, M. Chereches, L. Miron, S. Hudisteanu. Numerical study of cooling solutions inside a power transformer. Energy Procedia 112:314 321, 2017. DOI:10.1016/j.egypro.2017.03.1103.

[7] F. Torriano, H. Campelo, M. Quintela, et al. Numerical and experimental thermofluid investigation of different disc-type power transformer winding arrangements. International Journal of Heat and Fluid Flow 69:62 72, 2018. DOI:10.1016/j.ijheatfluidflow.2017.11.007

[8] G. R. Rodriguez, L. Garelli, M. Storti, et al. Numerical and experimental thermo-fluid dynamic analysis of a power transformer working in ONAN mode. Applied Thermal Engineering 112:1271 - 1280, 2017. DOI:10.1016/j.applthermaleng.2016.08.171

[9] P. A. Córdoba, E. Dari, N. Silin. A 3D numerical model of an ONAN distribution transformer. Applied Thermal Engineering 148:897 - 906, 2019. DOI:10.1016/j.applthermaleng.2018.11.098

[10] M. A. Tsili, E. I. Amoiralis, A. G. Kladas, A. T. Souflaris. Power transformer thermal analysis by using an advanced coupled 3D heat transfer and fluid flow FEM model. International Journal of Thermal Sciences 53:188 - 201, 2012. DOI:10.1016/j.ijthermalsci.2011.10.010

[11] S. Bouissou, F. Piriou, C. Kieny, G. Tanneau. Numerical simulation of a power transformer using 3D finite element method coupled to circuit equation. IEEE Transactions on Magnetics 30(5):3224 - 3227, 1994. DOI: $10.1109 / 20.312624$.
[12] L. Susnjic, Z. Haznadar, Z. Valkovic. 3D finite-element determination of stray losses in power transformer. Electric Power Systems Research 78(10):1814 - 1818, 2008. DOI:10.1016/j.epsr.2008.03.009.

[13] A. Ahmad, I. Javed, W. Nazar, M. A. Mukhtar. Short circuit stress analysis using FEM in power transformer on $\mathrm{H}-\mathrm{V}$ winding displaced vertically \& horizontally. Alexandria Engineering Journal 57(1):147 - 157, 2018. DOI:10.1016/j.aej.2016.10.006

[14] H. Ahn, Y. Oh, J. Kim, et al. Experimental verification and finite element analysis of short-circuit electromagnetic force for dry-type transformer. IEEE Transactions on Magnetics 48(2):819 - 822, 2012. DOI:10.1109/TMAG.2011.2174212.

[15] V. M. Jimenez-Mondragon, R. Escarela-Perez, E. Melgoza, et al. Quasi-3-D finite-element modeling of a power transformer. IEEE Transactions on Magnetics 53(6):1 - 4, 2017. DOI:10.1109/TMAG.2017.2659662

[16] C. Liao, J. Ruan, C. Liu, et al. 3-D coupled electromagnetic-fluid-thermal analysis of oil-immersed triangular wound core transformer. IEEE Transactions on Magnetics 50(11):1 - 4, 2014. DOI:10.1109/TMAG.2014.2330953

[17] K. Preis, O. Biro, G. Buchgraber, I. Ticar. Thermal-electromagnetic coupling in the finite-element simulation of power transformers. IEEE Transactions on Magnetics 42(4):999 - 1002, 2006. DOI:10.1109/TMAG.2006.871439

[18] Altair. AcuSolve ${ }^{\mathrm{TM}}$ - Finite element tool for computational fluid dynamics simulation. https://altairhyperworks . com/product/AcuSolve.

[19] Y. Jiao. CFD Study on the Thermal Performance of Transformer Disc Windings Without Oil Guides. Master's thesis, KTH School of Industrial Engineering and Management, Stockholm, 2012.

[20] C. E. V. Pontes, S. F. Costa, M. C. Costa, et al. Thermodynamic models and three-dimensional analysis for determination of load limits transformers. IEEE Latin America Transactions 11(5):1225 - 1231, 2013. DOI:10.1109/TLA.2013.6684397.

[21] K. S. Kassi, M.-I. Farinas, I. Fofana, C. Volat. Analysis of aged oil on the cooling of power transformers from computational fluid dynamics and experimental measurements. Journal of Applied Fluid Mechanics 9:235 - 243, 2016. 